\title{
Delayed diagnosis of pituitary stalk interruption syndrome with severe recurrent hyponatremia caused by adrenal insufficiency
}

\author{
Kyung Mi Jang, MD', \\ Cheol Woo Ko, MD, PhD²
}

${ }^{1}$ Department of Pediatrics, Yeungnam University College of Medicine, Daegu, ${ }^{2}$ Department of Pediatric Endocrinology, Kyungpook National University Children's Hospital, Daegu, Korea
Received: 25 July, 2017

Revised: 26 August, 2017

Accepted: 5 September, 2017

Address for correspondence:

Cheol Woo Ko, MD, PhD

Department of Pediatric Endocrinology, Kyungpook National University Children's Hospital, 130 Dongdeok-ro, Jung-gu, Daegu 41944, Korea

Tel: $+82-53-420-5715$

Fax: +82-53-425-6683

E-mail:cwko@knu.ac.kr

https://orcid.org/0000-0002-06437233
Pituitary stalk interruption syndrome (PSIS) involves the occurrence of a thin or absent pituitary stalk, hypoplasia of the adenohypophysis, and ectopic neurohypophysis. Diagnosis is confirmed using magnetic resonance imaging. Patients with PSIS have a variable degree of pituitary hormone deficiency and a wide spectrum of clinical manifestations. The clinical course of the disease in our patient is similar to that of a syndrome of inappropriate antidiuretic hormone secretion. This is thought to be caused by failure in the suppression of vasopressin secretion due to hypocortisolism. To the best of our knowledge, there is no case report of a patient with PSIS presenting with hyponatremia as the first symptom in Korean children. Herein, we report a patient with PSIS presenting severe recurrent hyponatremia as the first symptom, during adolescence and explain the pathophysiology of hyponatremia with secondary adrenal insufficiency.

Keywords: Pituitary stalk interruption syndrome, Hyponatremia, Hypopituitarism, Inappropriate ADH syndrome, Adrenal insufficiency

\section{Introduction}

Pituitary stalk interruption syndrome (PSIS) involves the occurrence of a thin or absent pituitary stalk, hypoplasia of the adenohypophysis, and ectopic neurohypophysis ${ }^{11}$. Diagnosis of this disease is confirmed using magnetic resonance imaging (MRI). PSIS was first reported in 1987 , based on MRI results ${ }^{1)}$. The incidence of this syndrome is approximately 0.5 per 100,000 births. Patients with PSIS patients have pituitary hormone deficiencies with variable timings of onset ${ }^{2}$. Hence, manifestations of PSIS have a wide spectrum of clinical phenotypes. For example, Olszewska et al. ${ }^{3)}$ published a case report of severe panhypopituitarism with PSIS in a newborn (4-day-old male) delivered by a mother with Turner Syndrome. Marmouch et al. ${ }^{4)}$ reported a case of late PSIS onset in which a 17 -year-old female patient presented primary amenorrhea and impuberism. Symptoms of PSIS can be overlooked during the neonatal period and infancy, therefore, diagnosis can be delayed.

Of the 2 posterior pituitary hormones, antidiuretic hormone (ADH) deficiency leads to diabetes insipidus. The major symptoms are polyuria, polydipsia, and nocturia. Under this condition, hypernatremia as well as extreme thirst can easily occur. However, diabetes insipidus may be masked when accompanied by an anterior pituitary hormone deficiency, such as ACTH deficiency, in which ADH is enhanced due to a cortisol deficiency ${ }^{5}$. Diederich et al. ${ }^{6}$ ) described the patient's illness as being similar to the syndrome of inappropriate antidiuretic hormone secretion (SIADH). To best of our knowledge, as of yet, there has been no report of severe hyponatremia associated with hypopituitarism in Korean children. Here, we report a patient with congenital hypopituitarism presenting with severe hyponatremia as the first symptom. 


\section{Case report}

At the age of 24 years, the patient was admitted to a university hospital with right upper quadrant pain and fever. He was suspected of having cholecystitis and was treated with intravenous (IV) antibiotics and NPO (nil per os). His symptoms improved after 2 days, but he was transferred to nephrology clinic of Kyungpook National University Hospital for uncorrected hyponatremia. After initial management, he was also referred to pediatric endocrinology clinic for short stature, hypogonadism, and hypothyroidism.

On admission, the patient's weight and height were $36.6 \mathrm{~kg}$ ( $<3 \mathrm{rd}$ percentile) and $146 \mathrm{~cm}$ ( $<3 \mathrm{rd}$ percentile), respectively, and he had a blood pressure of $108 / 60 \mathrm{mmHg}$. There was no evidence of dehydration, and his creatinine and uric acid levels were also within normal range. He showed no development of secondary sex characteristics, such as enlargement of testis and penis, or deepening of the voice. The grade of pubic hair was stage I on sexual maturity ratings, and his testicular volume was markedly decreased to $2-3 \mathrm{~mL}$. When we reviewed past medical history during childhood, we could see our patient already had markedly short stature and growth retardation. (Fig. 1). Laboratory examinations revealed profound hyponatremia at $114 \mathrm{mmol} / \mathrm{L}$, and a normal level of potassium at $4.0 \mathrm{mmol} /$ L. At that time, urinary sodium concentration was $87 \mathrm{mmol} /$

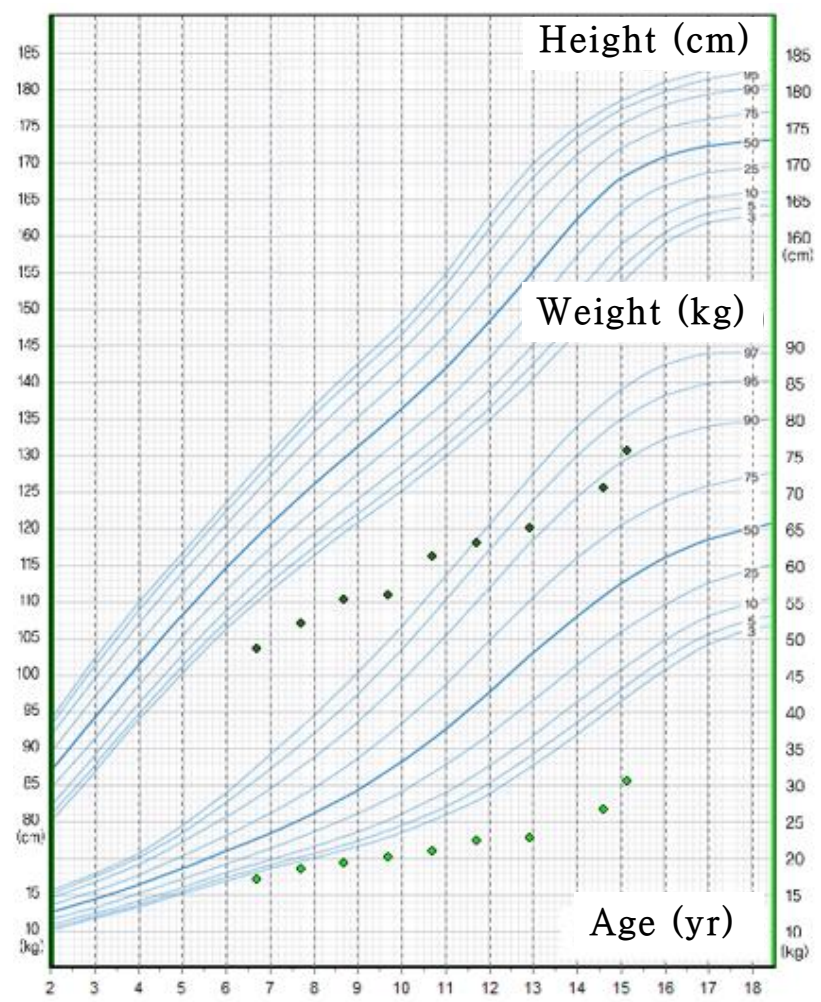

Fig. 1. The patient's height from 6 to 13 years of age was based on school physical records and was not measured in the last 8 years. The growth curve showed markedly short stature and growth rates less than $5 \mathrm{~cm} / \mathrm{yr}$ during childhood.
L. Unfortunately, his serum osmolarity and urine osmolarity were not measured upon admission. We checked serum/urine osmolarity and plasma arginine vasopressin (AVP). Laboratory findings showed that serum osmolarity and urine osmolarity levels were $285 \mathrm{mOsm} / \mathrm{kg}$ and $509 \mathrm{mOsm} / \mathrm{kg}$, respectively; urine osmolarity was markedly increased compared to serum osmolarity. Plasma AVP level was $8.96 \mathrm{pg} / \mathrm{mL}$ (normal, $<2.5$ $\mathrm{pg} / \mathrm{mL}$ ), showing a sustained elevation despite several days of hydrocortisone treatment due to low cortisol level.

He had been born without perinatal complication at 40 weeks of gestation and had a birth weight of 3,300 $\mathrm{g}$ by normal vaginal delivery. His parents denied the patient's hospitalization for hypoglycemia or seizure and micropenis during infant.

At the age of 14 years, this patient had been admitted for meningitis 10 years prior to his most recent admission. At that time, his laboratory results showed severe hyponatremia (115 $\mathrm{mmol} / \mathrm{L}$ ) without hyperkalemia (potassium at $3.5 \mathrm{mmol} / \mathrm{L}$ ) and he suffered a generalized tonic-clonic type seizure and was treated with mechanical ventilation for 6 days. Serum osmolarity and urine osmolarity levels were $249 \mathrm{mOsm} / \mathrm{kg}$ and $352 \mathrm{mOsm} /$ $\mathrm{kg}$, respectively, urinary sodium concentration was $103 \mathrm{mmol} /$ L. His hyponatremia was regarded as SIADH due to meningitis. He was treated with IV antibiotics, fluid restriction for SIADH and IV hydrocortisone for persistent hypotension. He was also diagnosed with hypothyroidism with free T4 levels at $0.10 \mathrm{ng} /$ $\mathrm{dL}$ (normal, $0.8-1.0 \mathrm{ng} / \mathrm{dL}$ ) and thyroid stimulating hormone (TSH) levels at $3.20 \mu \mathrm{IU} / \mathrm{mL}$ (normal, $0.3-4.0 \mu \mathrm{IU} / \mathrm{mL}$ ) and treated with $50 \mu \mathrm{g}$ of L-thyroxine. His symptoms improved, and he was discharged 2 weeks after hospitalization. The patient was advised to be readmitted for the evaluation of hypothyroidism and short stature. However, his hypothyroidism was treated at a local medical center irregularly at his own discretion, and he no longer visited our hospital.

On admission at 24 years of age, we measured 6 anterior pituitary hormones as well as the target hormone in the morning with fasting status. A thyroid function test revealed free T4 levels of $0.78 \mathrm{ng} / \mathrm{dL}$ (normal, $0.8-1.0 \mathrm{ng} / \mathrm{dL}$ ) and TSH levels of $1.45 \mu \mathrm{IU} / \mathrm{mL}$ (normal, $0.3-4.0 \mu \mathrm{IU} / \mathrm{mL}$ ) upon administration of $50 \mu \mathrm{g}$ of L-thyroxine. Laboratory examinations indicated a gonadotropin deficiency, showing a reduction in serum concentration of luteinizing hormone (LH) to $0.21 \mathrm{mIU} / \mathrm{mL}$ (normal, $1.5-9 \mathrm{mIU} / \mathrm{mL}$ ) and FSH to $1.1 \mathrm{mIU} / \mathrm{mL}$ (normal, $2.0-9.2 \mathrm{mIU} / \mathrm{mL}$ ). Fasting morning serum cortisol level was $5.59 \mu \mathrm{g} / \mathrm{dL}$ and insulin-like growth factor 1 level was $30.5 \mathrm{ng} /$ $\mathrm{mL}$ (normal, 83-344 ng/mL), which was also markedly low. These findings may suggest panhypopituitarism. To confirm the patient's disease, a combined pituitary function test and sella MRI were performed.

Combined pituitary function test was done. The patient was administered IV infusion with insulin (regular insulin, $0.1 \mathrm{IU} /$ $\mathrm{kg}$ ), thyrotropin-releasing hormone (TRH) (Protirelin tartrate $700 \mu \mathrm{g}$, Cerenyl, Bio \& Chemical R\&D, Seoul, Korea) and gonadotropin-releasing hormone $(\mathrm{GnRH})$ (gonadorelin $100 \mu \mathrm{g}$, Relefact LH-RH, Handok Pharmaceutical, Seoul, Korea) from separate syringes. Blood samples were collected at intervals 
Table 1. The results of combined pituitary function test

\begin{tabular}{lcccccccc} 
Variable & Glucose $(\mathrm{mg} / \mathrm{dL})$ & $\mathrm{TSH}(\mu \mathrm{lU} / \mathrm{mL})$ & $\mathrm{PRL}(\mathrm{ng} / \mathrm{mL})$ & $\mathrm{LH}(\mathrm{mlU} / \mathrm{mL})$ & $\mathrm{FSH}(\mathrm{mlU} / \mathrm{mL})$ & $\mathrm{HGH}(\mu \mathrm{g} / \mathrm{L})$ & $\mathrm{Cortisol}(\mu \mathrm{g} / \mathrm{dL})$ & $\mathrm{ACTH}(\mathrm{pg} / \mathrm{mL})$ \\
\hline Basal & 84 & 1.1 & 10.09 & 0.21 & 1.10 & 0.01 & 7.02 & 27.98 \\
$30 \mathrm{Min}$ & 42 & 8.11 & 23.6 & 0.85 & 1.35 & 0.02 & 6.54 & 30.07 \\
$60 \mathrm{Min}$ & 40 & 10.35 & 23.4 & 1.96 & 1.82 & 0.01 & 6.54 & 19.27 \\
$90 \mathrm{Min}$ & 36 & 10.48 & 18.1 & 0.85 & 2.12 & 0.02 & 6.37 & 33.24 \\
$120 \mathrm{Min}$ & 43 & 10.09 & 14.9 & 0.85 & 2.39 & 0.06 & 10.7 & 42.02 \\
\hline
\end{tabular}

$\mathrm{TSH}$, thyroid stimulating hormone; PRL, prolactin; LH, luteinizing hormone; FSH, follicle stimulating hormone; HGH, human growth hormone; ACTH, adrenocorticotropic hormone.

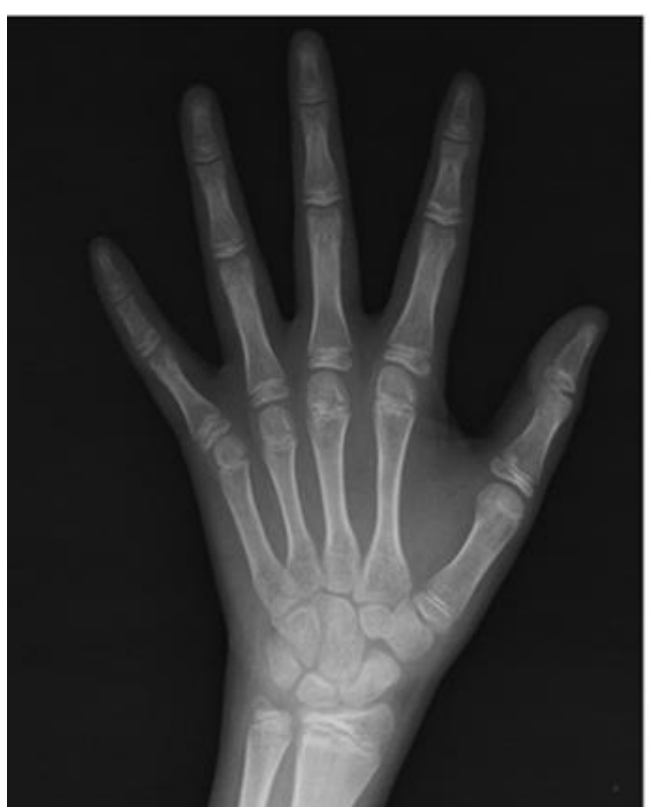

Fig. 2. The left-hand anteroposterior view represents between 14 and 15 years of bone age using the standards of the Greulich-Pyle method, which is delayed compared to chronological age of 24 year-old.

of $0,30,60,90$, and 120 minutes for assay of the respective hormones. Combined pituitary function test showed decreased growth hormone (peak GH, $0.06 \mu \mathrm{g} / \mathrm{L}$; normal range, $>5 \mu \mathrm{g} /$ $\mathrm{L}$ ) and cortisol (peak cortisol, $10.7 \mu \mathrm{g} / \mathrm{dL}$; normal range, $>22$ $\mu \mathrm{g} / \mathrm{dL}$ ) secretion to insulin-induced hypoglycemia. This is compatible with complete growth hormone deficiency (GHD) and adrenocortical insufficiency. TSH (peak TSH, $10.48 \mathrm{uIU} /$ $\mathrm{mL}$; normal range, $>10-30 \mu \mathrm{IU} / \mathrm{mL}$ ) showed partial response to TRH. Peak LH and FSH were $1.96 \mathrm{mIU} / \mathrm{mL}$ and $2.39 \mathrm{mIU} /$ $\mathrm{mL}$, respectively, following stimulation with $\mathrm{GnRH}$. This result indicated that the patient was diagnosed with multiple pituitary hormone deficits (Table 1).

We checked the left-hand anteroposterior view. The patient's bone age, which we determined was between 14 and 15 years using the standards of the Greulich-Pyle method and delayed when compared to his chronological age of 24 years (Fig. 2). His MRI findings showed an absence of pituitary stalk, hypoplasia of the adenohypophysis, and an absence of posterior pituitary gland, indicative of pituitary stalk syndrome (Fig. 3). The patient was treated with hydrocortisone, and his hyponatremia was quickly normalized in response to medication during both

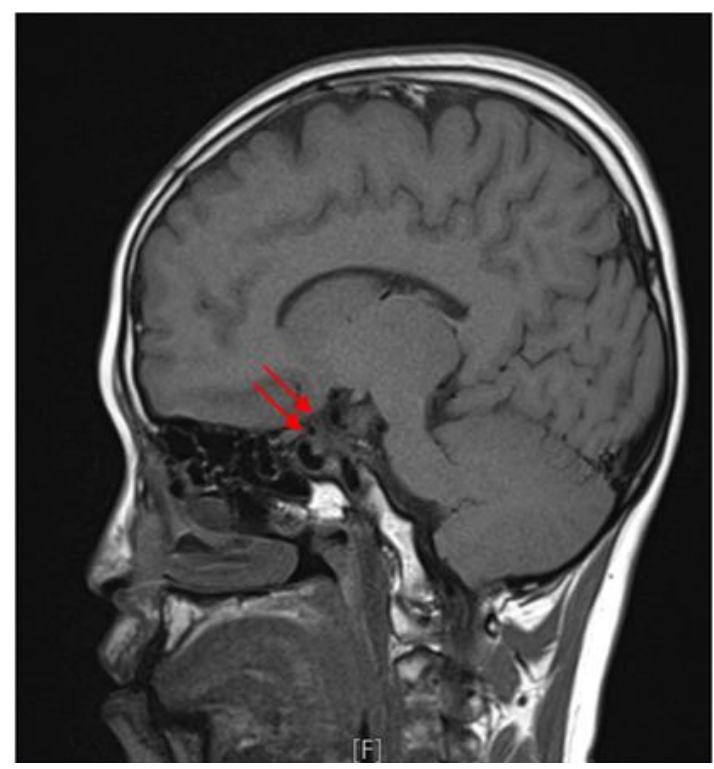

Fig. 3. The arrows indicate absent pituitary stalk, hypoplasia of the adenohypophysis, and absent posterior pituitary gland on sella magnetic resonance imaging.

the first and second hospitalizations (Fig.4). L-thyroxine was increased from 50 to $75 \mu \mathrm{g}$, and growth hormone therapy was also started.

Written informed consent was obtained from the patient.

\section{Discussion}

Hyponatremia is one of the most common electrolyte imbalances; however, symptoms may vary depending on underlying etiology. Some cases can be asymptomatic, but severe hyponatremia can be fatal. Bartter and Schwartz ${ }^{7)}$ described patients with SIADH who have an inappropriate vasopressin secretion' despite euvolemia. SIADH excludes causes by hypopituitarism and adrenal insufficiency, but there are some cases similar to SIADH in patients with hypopituitarism ${ }^{8)}$. Diederich et al. ${ }^{6}$ describe the patients as 'SIADH-like syndrome'.

Glucocorticoid physiologically suppresses corticotropinreleasing hormones and vasopressin secretion in hypothalamic neurons ${ }^{9,10)}$. Furthermore some studies reported that hyponatremia with hypopituitarism developed in patients because of failure in the suppression of vasopressin secretion due to hypocortisolism ${ }^{11,12)}$. This hyponatremia occurs commonly 

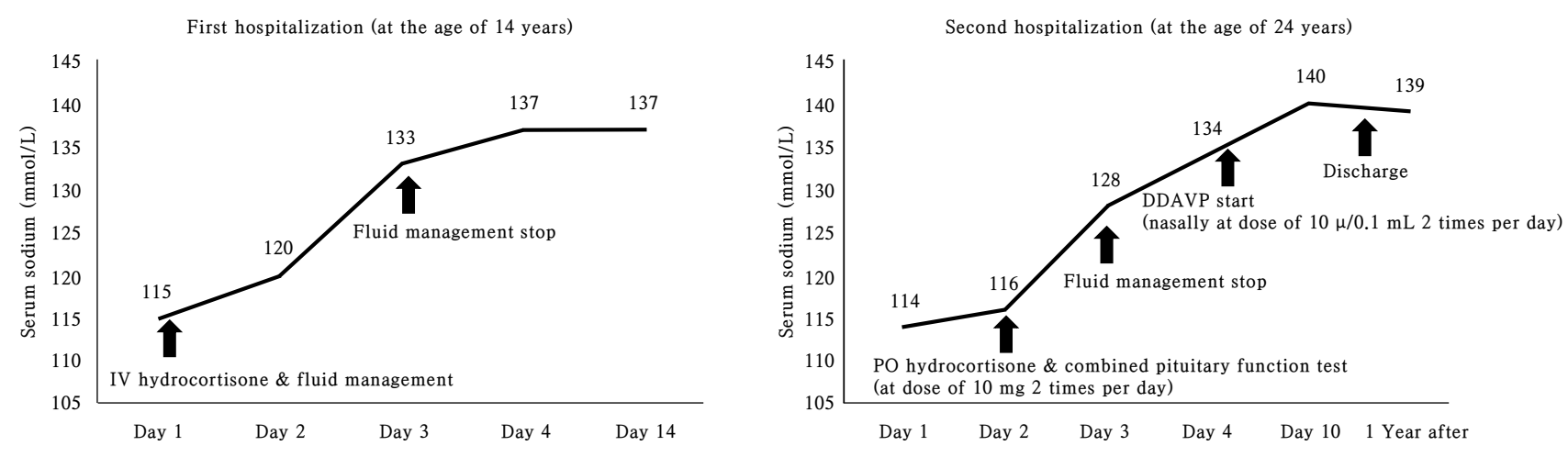

Fig. 4. Serial change of serum sodium levels during the twice hospitalization of a patient with PSIS; first admission at the age of 14 years (A) and second admission at the age of 24 years (B). PSIS, pituitary stalk interruption syndrome; DDAVP, 1-desamino-8-Darginine vasopressin.

in ACTH deficient patients without diabetes insipidus. When glucocorticoid therapy is started, diabetes insipidus may become manifest because of suppressing vasopressin by hydrocortisone and enables normal electrolyte-free water excretion ${ }^{6,13)}$.

At the age of 14 years old, the patient had drowsy mentality and hypotension which implied adrenal crisis. On the second admission, he did not show any symptoms of adrenal crisis, but he suffered from euvolemic hyponatremia and was also under an acute stress event such as cholecystitis. The patient could not overcome a normal physiological response with increase of endogenous cortisol production in both situations. With the failure to increase endogenous cortisol production, hypocortisolism worsened and hyponatremia occurred, similar to SIADH, due to failure to suppress vasopressin. Although the clinical course is similar to that of SIADH, the treatment is completely different. The main treatment of SIADH is fluid management, however, patients with 'SIADH-like syndrome' respond poorly to fluid management and hyponatremia is corrected by hydrocortisone administration. These patients with hypopituitarism also did not develop hyperkalemia and hyperreninemia because although aldosterone secretion may be slightly decreased in hypopituitarism due to ACTH deficiency, the residual aldosterone, which is regulated by the renin/angiotensin system, is enough to maintain normal plasma volume $e^{5}$. Our patient also developed diabetes insipidus when glucocorticoid therapy (at a dose of $10 \mathrm{mg} 2$ times per day) was started. He was administered DDAVP (1-desamino8-D-arginine vasopressin) nasally at doses of $10 \mu \mathrm{g} / 0.1 \mathrm{~mL}$ 2 times per day and his symptoms improved. Since then, hydrocortisone was continued at a dose of $10 \mathrm{mg} 2$ times per day. Deodati and Cianfarani ${ }^{14)}$ have been reported that adult height is considered achieved when a growth rate is $<1.5 \mathrm{~cm} /$ $\mathrm{yr}$, or bone age $>15$ years in girls and $>16$ years in boys. Some studies reported that testosterone might advance bone age ${ }^{15,16)}$. At a height of $146 \mathrm{~cm}$, the patient had a very short stature, considering his age. Therefore, growth hormone therapy (at a dose of $0.3 \mathrm{mg} / \mathrm{kg} / \mathrm{wk}$ ) was started at between 14 and 15 years of bone age and testosterone supplementation was held until his bone age reached 16 years old. Recombinant human GH
(rhGH) was started with conventional dose $(0.3 \mathrm{mg} / \mathrm{kg} / \mathrm{wk})$ used in patient with $\mathrm{GHD}^{17}$. One study reported that high dose rhGH treatment in patient with GHD in puberty increased final height ${ }^{18)}$. After several months of rhGH use, if the response is not adequate, we also have plan to increase up to high dose ( 0.7 $\mathrm{mg} / \mathrm{kg} / \mathrm{wk})$.

The pathogenesis of PSIS remains elusive. Traumatic birth was suggestive of the etiology, considering the high frequency of perinatal events in patients with PSIS. Recent studies had reported organogenesis defects, especially midline defects, suggesting genetic alterations as the underlying mechanism ${ }^{19}$. Most cases of PSIS are sporadic and occasionally familial, because most patients with PSIS have hypogonadism ${ }^{20)}$. Our patient is also considered sporadic because his mother's height was about $155 \mathrm{~cm}$ and father's height was $167 \mathrm{~cm}$ and they denied hospitalization due to serious illness. Their appearance also looked normal. Mutations of transcriptional factor genes associated with pituitary development have been reported. The genes PROP1, LHX3/LHX4, PIT1, PROKR2, OTX2, HESX1 and TGIF were reported in some studies ${ }^{19,20)}$. Unfortunately, we had no genetic testing results.

The true prevalence of hyponatremia associated with cortisol deficiency is unknown. Cuesta et al. ${ }^{12)}$ reported 573 patients with SIADH. Of the 573 patients, 22 (3.8\%) were initially diagnosed with SIADH, then reclassified having secondary adrenal insufficiency based on laboratory findings and clinical presentation. The author also emphasized that adrenal insufficiency might be an underrecognized cause of hyponatremia. Secondary adrenal insufficiency should be highly suspected in patients with hyponatremia, but without hyperkalemia. Verbalis et al. ${ }^{13)}$ recommends measuring cortisol at $9 \mathrm{AM}$ in hyponatremia. The level of cortisol is under $10 \mu \mathrm{g} /$ $\mathrm{dL}$, then is not physiological in acutely ill patients. Secondary adrenal insufficiency should be primarily verified in these patients.

Some cases of hyponatremic hypopituitarism have been reported in Korea, but most of the reports are associated with Sheehan's syndrome, hemorrhagic fever, and brain masses in adults. 
To the best of our knowledge, this patient is the first case of PSIS in Korea that occurred during adolescence and presented severe hyponatremia associated with secondary adrenal insufficiency as the first symptom.

\section{Conflict of interest}

No potential conflict of interest relevant to this article was reported.

\section{References}

1. Fujisawa I, Kikuchi K, Nishimura K, Togashi K, Itoh K, Noma S, et al. et al. Transection of the pituitary stalk: development of an ectopic posterior lobe assessed with MR imaging. Radiology 1987;165:487-9.

2. Arrigo T, Wasniewska M, De Luca F, Valenzise M, Lombardo F, Vivenza D, et al. Congenital adenohypophysis aplasia: clinical features and analysis of the transcriptional factors for embryonic pituitary development. J Endocrinol Invest 2006;29:208-13.

3. Olszewska M, Kiełbasa G, Wójcik M, Zygmunt-Górska A, Starzyk JB. A case report of severe panhypopituitarism in a newborn delivered by a women with Turner syndrome. Neuro Endocrinol Lett 2015;36:734-6.

4. Marmouch H, Graja S, Arfa S, Boubaker F, Khochtali I. Late-onset pituitary stalk interruption syndrome (PSIS). Pan Afr Med J 2016;23:108.

5. Kim SY. Diagnosis and treatment of hypopituitarism. Endocrinol Metab (Seoul) 2015;30:443-55.

6. Diederich S, Franzen NF, Bähr V, Oelkers W. Severe hyponatremia due to hypopituitarism with adrenal insufficiency: report on 28 cases. Eur J Endocrinol 2003;148:609-17.

7. Bartter FC, Schwartz WB. The syndrome of inappropriate secretion of antidiuretic hormone. Am J Med 1967;42:790806.

8. Oelkers W. Hyponatremia and inappropriate secretion of vasopressin (antidiuretic hormone) in patients with hypopituitarism. N Engl J Med 1989;321:492-6.

9. Erkut ZA, Pool C, Swaab DF. Glucocorticoids suppress corticotropin-releasing hormone and vasopressin expression in human hypothalamic neurons. J Clin Endocrinol Metab 1998;83:2066-73.
10. Raff H. Glucocorticoid inhibition of neurohypophysial vasopressin secretion. Am J Physiol 1987;252(4 Pt 2):R63544.

11. Puar TH, Stikkelbroeck NM, Smans LC, Zelissen PM, Hermus AR. Adrenal crisis: still a deadly event in the 21st century. Am J Med 2016;129:339.e1-9.

12. Cuesta M, Garrahy A, Slattery D, Gupta S, Hannon AM, Forde $\mathrm{H}$, et al. The contribution of undiagnosed adrenal insufficiency to euvolaemic hyponatraemia: results of a large prospective single-centre study. Clin Endocrinol (Oxf) 2016;85:836-44.

13. Verbalis JG, Goldsmith SR, Greenberg A, Korzelius C, Schrier RW, Sterns RH, et al. Diagnosis, evaluation, and treatment of hyponatremia: expert panel recommendations. Am J Med 2013;126(10 Suppl 1):S1-42.

14. Deodati A, Cianfarani S. Impact of growth hormone therapy on adult height of children with idiopathic short stature: systematic review. BMJ 2011;342:c7157.

15. Damiani D, Damiani D. Pharmacological management of children with short stature: the role of aromatase inhibitors. J Pediatr (Rio J) 2007;83(5 Suppl):S172-7.

16. Kwon JH, Lee HA, Kim YJ, Lee H, Park EA, Cho SJ, et al. Effects of adrenal androgen levels on bone age advancement in prepubertal children: using the Ewha Birth and Growth Cohort Study. J Korean Med Sci 2017;32:96873 .

17. John S, PaE I, Felner. In: Kliegman RM, Stanton B, St. Geme J, Schor N, Behrman RE. Nelson textbook of pediatrics. 20th ed. Philadelphia: Elsevier Saunders, 2016:2642-3.

18. Mauras N, Attie KM, Reiter EO, Saenger P, Baptista J. High dose recombinant human growth hormone $(\mathrm{GH})$ treatment of GH-deficient patients in puberty increases near-final height: a randomized, multicenter trial. Genentech, Inc., Cooperative Study Group. J Clin Endocrinol Metab 2000; 85:3653-60.

19. Reynaud R, Albarel F, Saveanu A, Kaffel N, Castinetti F, Lecomte $\mathrm{P}$, et al. Pituitary stalk interruption syndrome in 83 patients: novel HESX1 mutation and severe hormonal prognosis in malformative forms. Eur J Endocrinol 2011;164:457-65.

20. Wang CZ, Guo LL, Han BY, Su X, Guo QH, Mu YM. Pituitary stalk interruption syndrome: from clinical findings to pathogenesis. J Neuroendocrinol 2017;29. https://doi. org/10.1111/jne.12451. 